\title{
TOPICAL CHEMOPREVENTIVE EFFECT OF THYMOQUINONE VERSUS THYMOQUINONE LOADED ON GOLD NANOPARTICLES ON DMBA-INDUCED HAMSTER BUCCAL POUCH CARCINOGENESIS (IMMUNOHISTOCHEMICAL STUDY)
}

\author{
Wafaa H. El-Hossary*, Enas Hegazy ${ }^{* *}$ and Merhan N. El-Mansy*
}

\begin{abstract}
Background: oral cancer is the third most common cancer in developing countries. Thymoquinone has a powerful anticancer, antioxidant, and anti-inflammatory properties.

Aim: To compare the topical chemopreventive effect of thymoquinone (TQ) versus thymoquinone loaded on gold nanoparticles (GNPs-TQ) on DMBA-induced oral carcinogenesis through histological and immunohistochemical expression of p53.
\end{abstract}

Material \& methods: Characterization of the prepared drugs was done through transmission electron microscope, and Ultraviolet-Visible spectroscope. Experimental design: The study was carried out on forty male Syrian golden hamsters, weighing 90-100 grams. Negative control group A $(n=10)$ didn't receive any type of treatment till the end of experiment. Positive control group B $(n=10)$ was painted with DMBA, 3times/week for 14 weeks. Group $C(n=10)$ was daily painted by topical application of TQ for two weeks, and then painted with both TQ and DMBA on alternative days for 14 weeks. Group D ( $\mathrm{n}=10)$ had been managed as group C but TQ was replaced by GNPsTQ. These groups was examined histologically and immunohistochemically through expression of p53.

Results: Proper loading of TQ on GNPs was confirmed. Histopathological evaluation showed superior effect of GNPs-TQ in retardation of carcinogenesis compared to free TQ. Immunohistochemical evaluation revealed significant decrease in P53 expression in the group treated with GNPs-TQ than TQ in comparison with positive control group.

Conclusions: GNPs-TQ is a promising chemo-preventive agent of oral cancer through topical application.

KEY WORDS: Oral cancer, DMBA, Thymoquinone, GNPs-TQ, and p53

* Oral Pathology Department, Faculty of Dentistry, Suez Canal University.

** Oral Biology Department, Faculty of Dentistry, Suez Canal University. 


\section{INTRODUCTION}

Oral squamous cell carcinoma (OSCC) is the most common malignancy of the head and neck. ${ }^{1}$ Every year in Egypt, approximately 4.500 people are diagnosed with oral cancer; about half of them would die because of the disease. ${ }^{2}$ Once the cell damage become irreversible due to various risk factors, it would be manifested as dead cell or neoplastic transformation. ${ }^{3}$ The neoplastic transformation may lead to genetic alterations and altered cell cycle regulation. ${ }^{4}$ 7,12-dimethylbenz(a)-anthracene (DMBA) is widely used carcinogen in experimental oral carcinogenesis through formation of DNA adducts, DNA damage, inhibition of DNA repair enzymes, generation of excess reactive oxygen species and production of chronic inflammation. ${ }^{5}$ Cancer chemoprevention uses natural, synthetic, or biologic chemical agents to reverse, suppress, or prevent carcinogenic progression. ${ }^{6}$

Thymoquinone is considered the main active constituent of Nigella sativa L. ${ }^{7}$ It was documented that TQ inhibits various cancer hallmarks as tumor cell proliferation, inflammation, cancer cell death, tumor angiogenesis, invasion and metastasis. ${ }^{8}$ Majdalawieh et al represented the anti-tumor effect of TQ alone in vitro and in vivo studies. ${ }^{9}$ Poor bioavailability of TQ is the main complication. So, nano-carriers were prepared to modify the drug's bioavailability, efficacy, stability and toxicity associated with high doses. ${ }^{1{ }^{\prime} 11}$ GNPs could be easily synthesized with different shapes and characterized due to the characteristic Surface Plasmon Resonance (SPR) bands. ${ }^{12}$ P53 is considered the guardian of the genome because of the adaptive and protective cellular responses which prevent cellular proliferation. ${ }^{13}$ Any mutation in p53 is considered an early event of carcinogenesis; its accumulation is associated with poorer differentiation and malignancy. ${ }^{14}$ The present study attempted to compare the topical chemo-preventive effect of TQ versus GNPs-TQ in DMBA-induced hamster buccal pouch carcinogenesis through histological examination and immunohistochemical detection of p53.

\section{MATERIAL AND METHODS}

Preparation of thymoquinone loaded on gold nanoparticles: Tetrachloroauric acid $\left(\mathrm{HAuCl}_{4}\right)$, trisodium citrate $\left(\mathrm{Na}_{3} \mathrm{C}_{6} \mathrm{H}_{5} \mathrm{O}_{7}\right)$, thymoquinone $\left(\mathrm{C}_{10} \mathrm{H}_{12} \mathrm{O}_{2}\right)$, and propylenegylcol $\left(\mathrm{C}_{3} \mathrm{H}_{8} \mathrm{O}_{2}\right)$ were purchased from Sigma Chemical Company, St. Louis, Mo, USA. GNPs were prepared by Turkevich method. ${ }^{15}$ Tetrachloroauric acid was heated until boiling with stirring, and then trisodium citrate was injected. The gold nanoparticles were gradually formed as indicated by the change in color from pale yellow to deep red color. Thymoquinone solution of $0.01 \mathrm{mg} / \mathrm{kg}$ was dissolved in propylene gylcol with the aid of a magnetic stirrer for 2 hours. The loading of thymoquinone on GNPs was achieved by mixing equal amount of both, stirred for 2 hours then kept in $5^{\circ} \mathrm{C}$.

High resolution transmission electron microscope (TEM) was used to study the morphology of GNPs, GNPs-TQ using JEOL JEM 2100 (Japan). Pictures of nanoparticles were taken in the Egyptian Petroleum Research Institute. TEM operating at a magnification of $80 \mathrm{kV}$ with $1 \mathrm{~K} \times 1 \mathrm{~K}$ digital images captured using an AMT CCD camera (Danvers, MA). For GNPs, a drop was placed on a paraffin sheet; a copper grid was placed on the sample and left for 1 minute to allow NPs to adhere. For GNPs-TQ, the grid was placed on a drop of phosphotungstate for 5 minutes. The remaining solution was removed by absorbing the liquid with a piece of filter paper, samples were air dried, then examined by TEM. Ultraviolet-Visible (UV-vis) spectroscope was used to determine the maximum absorption of ultraviolet for GNPs, TQ, and GNPsTQ at room temperature in a quartz cuvette using T90+UV-VIS Spectrometer (PG Instruments Ltd). Its wavelength ranges from $250-850 \mathrm{~nm}$. 


\section{Experimental design:}

The chemical carcinogen DMBA was dissolved in heavy mineral oil to get solution of $0.5 \%$ concentration. Both of them were purchased from Sigma Chemical Company, St. Louis, Mo, USA. The carcinogen was topically applied to hamster buccal pouch by using number (4) camel hair brush. The experiment was done at the animal house of Faculty of Dentistry, Suez Canal University, Ismailia. The study was carried out on forty Syrian male golden hamsters, weighing 90-100 grams. The animals were purchased from, Tiedor Blhars Research Institute, Cairo, Egypt. The animals were housed (five per cage) at controlled temperature; all animals were given water and recommended nutrient, ad libitum, and were divided as follow: Negative control group A $(n=10)$ didn't receive any type of treatment till the end of experiment. Five animals were sacrificed at day zero and five animals were sacrificed at $14^{\text {th }}$ week. Positive control group $\mathbf{B}(n=10)$ the left cheek pouch was painted with DMBA, thrice/week for 14 weeks. Group C $(n=10)$ the left cheek pouch was daily painted by topical application of TQ $0.01 \mathrm{mg} / \mathrm{kg}$ for two weeks, and then painted with both TQ and DMBA on alternative days for 14 weeks. Group D $(\mathrm{n}=10)$ the left cheek pouch was daily painted by topical application of GNPs-TQ $0.01 \mathrm{mg} / \mathrm{kg}$ for two weeks, and then painted with both GNPs-TQ and DMBA on alternative days for 14 weeks.

\section{Histopathological evaluation:}

The left pouches were surgically removed after euthenization, fixed in $10 \%$ neutral formalin solution, processed, embedded in paraffin, sectioned into $5 \mu \mathrm{m}$, mounted on glass slides and stained with hematoxylin \& eosin for light microscopic study, then photographed by E-330 Olympus digital camera. Grading of epithelial dysplasia was carried out according to Banoczy and Sciba $(1976)^{16}$ and modified by El-Dakhakhny et al (2010) ${ }^{17}$ due to thin nature of hamsters' epithelial lining. Grading of squamous cell carcinoma was done according to Broder's classification. ${ }^{18}$

\section{Immunohistochemical evaluation (IHC):}

From each paraffin block, $5 \mu \mathrm{m}$ sections were cut and mounted on positively-charged slides. The antibody used was p53; rabbit polyclonal antibody which purchased from Gene Tex International Corporation, Cat. No. GTX100629, with brown nuclear expression. The steps of IHC followed according to manufacturer's instructions. Image analyzer software (image J / figi 1.46) was used to count the number of immunopositive cells as well as the number of the remaining unstained ones. The percent of the positive cells was calculated.

\section{Statistical analysis:}

Microsoft excel 2013 was used for data entry and the statistical package for social science (SPSS) version 24 was used for data analysis. All values were expressed as mean \pm standard deviation. Comparisons between groups were performed using one-way analysis of variance (ANOVA). Probability value less than 0.001 was considered significant.

\section{RESULTS}

\section{I- Characterization of GNPs-TQ:}

Citrate ions acted as both a reducing agent and a capping agent. Once they settled on the particle surface, GNPs were stabilized trough electrostatic repulsion. Color change from pale yellow color to deep red color confirmed GNPs formation. TEM micrographs revealed that GNPs were spherical and well dispersed without agglomeration, with average size $25-30 \mathrm{~nm}$ in size (figure 1-A). The loading of TQ on GNPs was represented in figure 1-B. UV-visible spectrometer results showed sharp peak was given by UV-visible spectrum for GNPs at $\lambda \max =526 \mathrm{~nm}$ (figure $1-\mathrm{C}$ ) which confirmed the nanoparticles formation. GNPs-TQ gave maximum absorption peak $\lambda \max =532 \mathrm{~nm}$ (figure $1-\mathrm{D}$ ). This 
deviation in the maximum peak confirmed loading of TQ on GNPs.

II-Clinical findings: Animals in negative control group (A) showed no gross changes throughout the experimental period. Their buccal pouch lengths were about $5 \mathrm{~cm}$ for all hamsters. Animals in the positive control group (B) showed marked hair loss, pouch depth decrease, skin ulcers and marked debilitation of all animals. Animal's pouches showed large exophytic growths with pronounced vascularity and the pouch length ranged from 1.5$2 \mathrm{~cm}$. The animals in the group D painted with GNPsTQ showed significant improvement in comparison with animals in the group $\mathrm{C}$ painted with TQ only. There was marked decrease in the size of the lesions and the pouch length reached $3.5 \mathrm{~cm}$. (figure 2).
III-Histopathological findings: Group A (negative control) revealed normal thin stratified squamous epithelium formed of two to four cell layers, lacking rete ridges and thin keratin surface layer. The underlying connective tissue (c.t.) showed non inflamed loose connective tissue, with thin vascular spaces. Deeper c.t. layer was formed of larger vessels and longitudinal striated muscle layer (figure 3-A). Group B (positive control) showed well to moderate differentiated squamous cell carcinomas in the form of papillomatous lesions with invading islands of epithelium into underlying connective tissuse. The invading epithelial cells showed basal cell hyperplasia, loss of basal cells polarity, hyperchromatism, prominent nucleoli, altered $\mathrm{N} \backslash \mathrm{C}$ ratio, swirling of spinous layer and cellular $\&$ nuclear pleomorphism. Connective tissue was

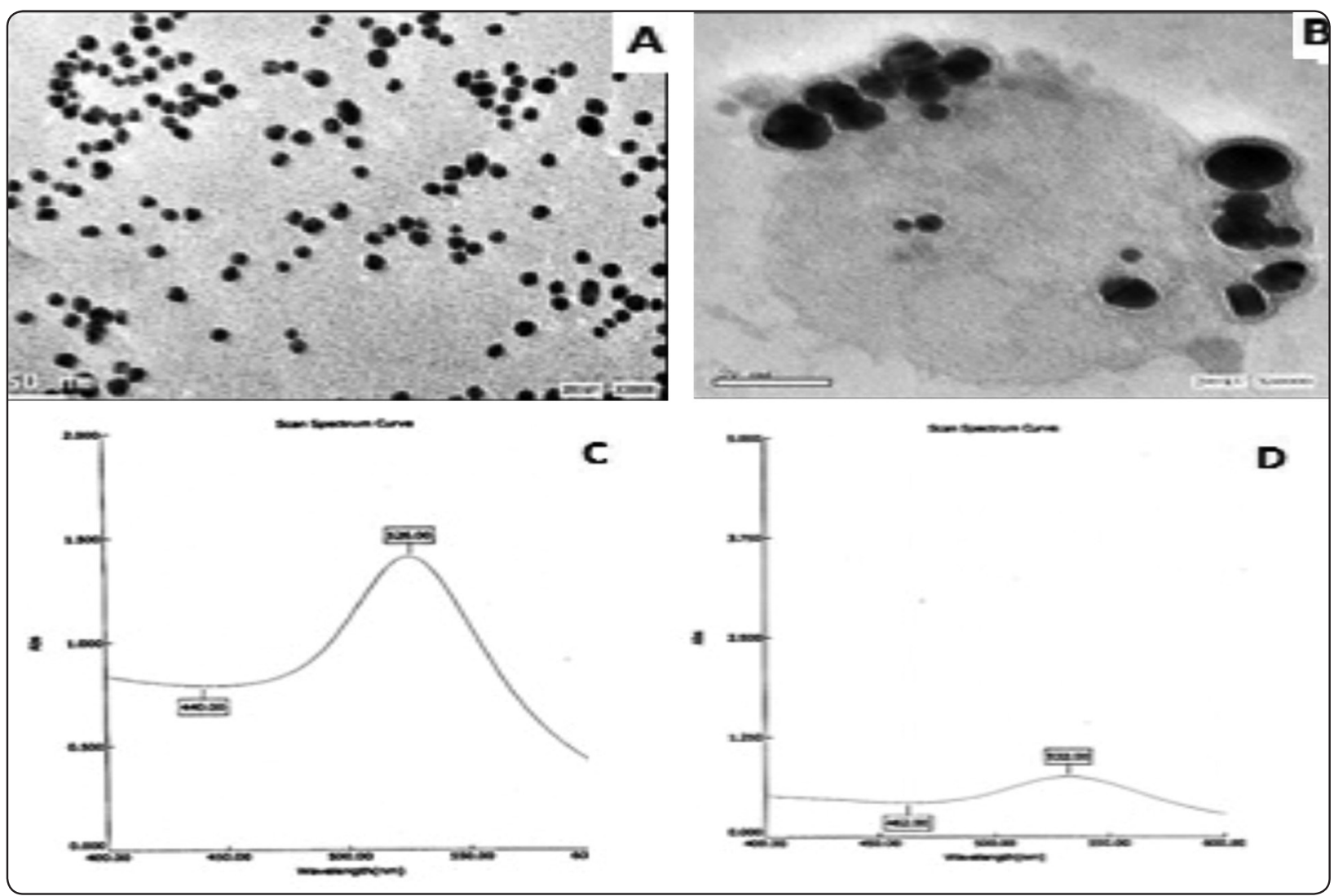

Fig. (1) Showing characterization of GNPs- TQ, (A) GNPs appear spherical, well dispersed without agglomeration, (B) the proper loading of TQ on GNPsl (C) sharp peak of UV -visible spectrum for GNPs at 526nm, (D) sharp peak of UV-visible spectrum for GNPs-TQ at $532 \mathrm{~nm}$. 


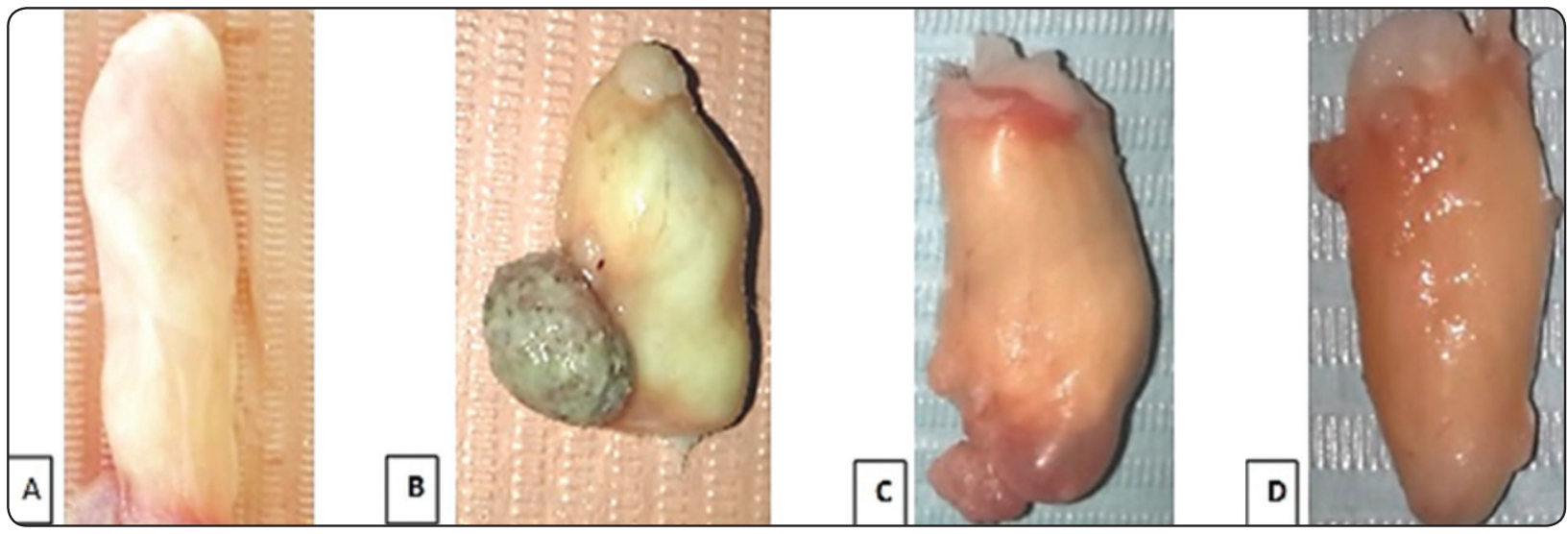

Fig. (2) Showing different sizes of the lesions (A) normal pouch length within 5cm in untreated group, (B) large exophytic masses with marked shortening of the pouch to about $1.5 \mathrm{~cm}$ in positive control group, (C) moderate-sized exophytic masses when painted with TQ alone, CD) small exophytic mass when painted with GNPs- TQ with marked increase in pouch length.

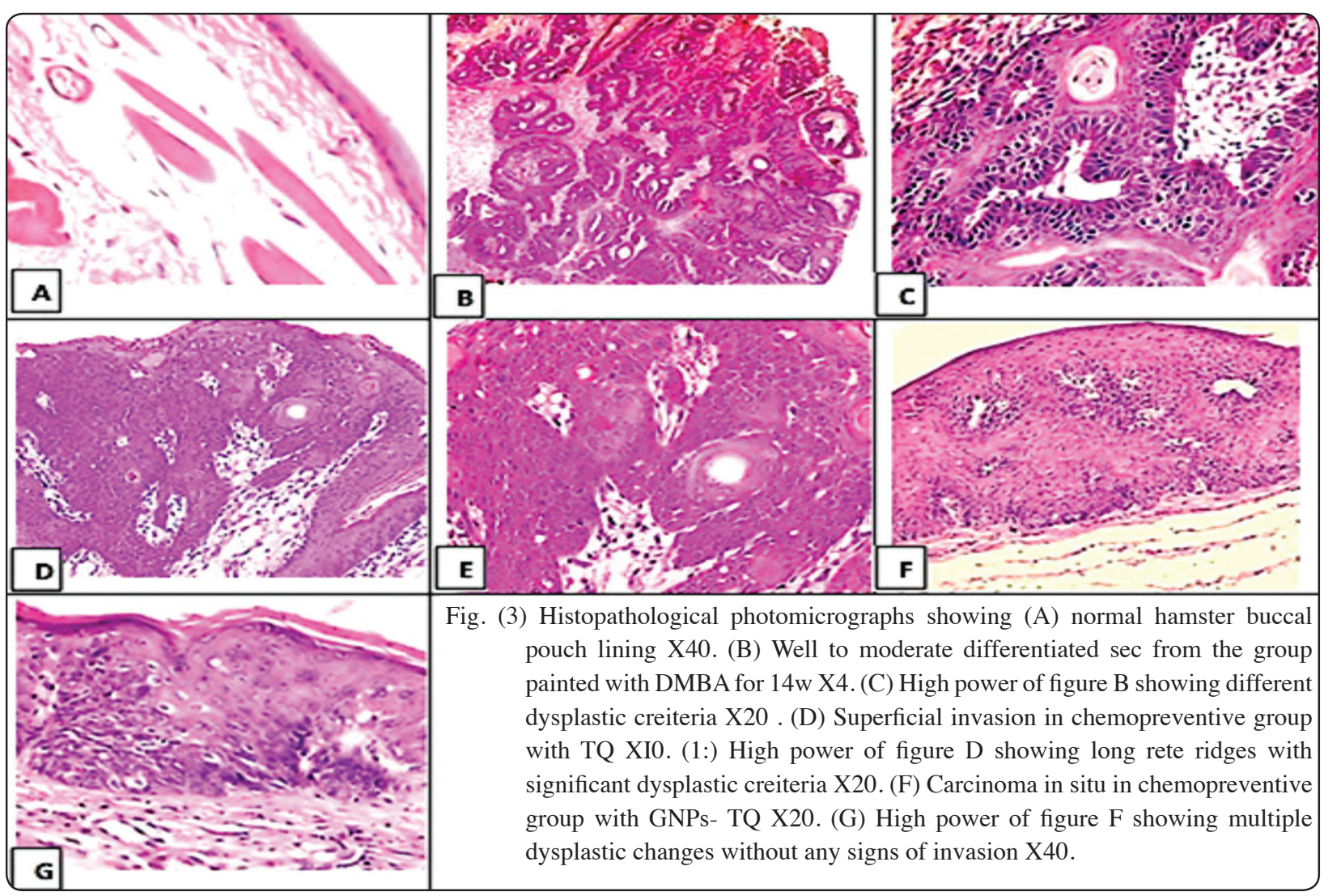


invaded with keratin pearl and dysplastic epithelial nests (figure $3 \mathrm{~B} \& \mathrm{C}$ ). Group $\mathrm{C}$ (painted with TQ only) showed superficial invasive carcinoma with multiple signs of dysplasia. The invasive islands were located below the papillomatous lesion directly (figure 3 D\&E). Group D (painted with GNPs-TQ) revealed carcinoma in situ only without any signs of invasion. The epithelium showed severe cellular and architectural changes as basal cell hyperplasia and loss of polarity, hyperchromatism, altered N/C ratio and cellular/nuclear pleomorphism (figure 3 $\mathrm{F} \& \mathrm{G})$.

\section{IV-Immunohistochemical (IHC) assessment:}

By examining the negative control group, p53 nuclear expression was not detectable (figure 4-A). Examining the DMBA-painted group revealed marked increase in the nuclear p53 expression suprabasally, extended allover epithelium thickness (figure 4-B\&C). In the group painted with TQ only, there was a slight dwindle in the nuclear expression of p53 (figure 4-D\&E). Noteworthy, there was a significant decrease of p53 nuclear expression in the group painted with GNPs-TQ (figure 4-F\&G).

V-Statistical results evaluation: (table 1) regarding $\mathrm{p} 53$, there was a high statistical significant difference between whole groups (P-value $<0.001$ ) through using Annova - one way test (figure 5). The most statistically significant result was associated with the group painted with GNPs-TQ [15.82 \pm 1.65] in comparison with the group painted with TQ only [25.48 \pm 3.84$]$. Also, both of chemopreventive drugs showed statistically significant result versus positive control group [47.01 \pm 6.79$]$.

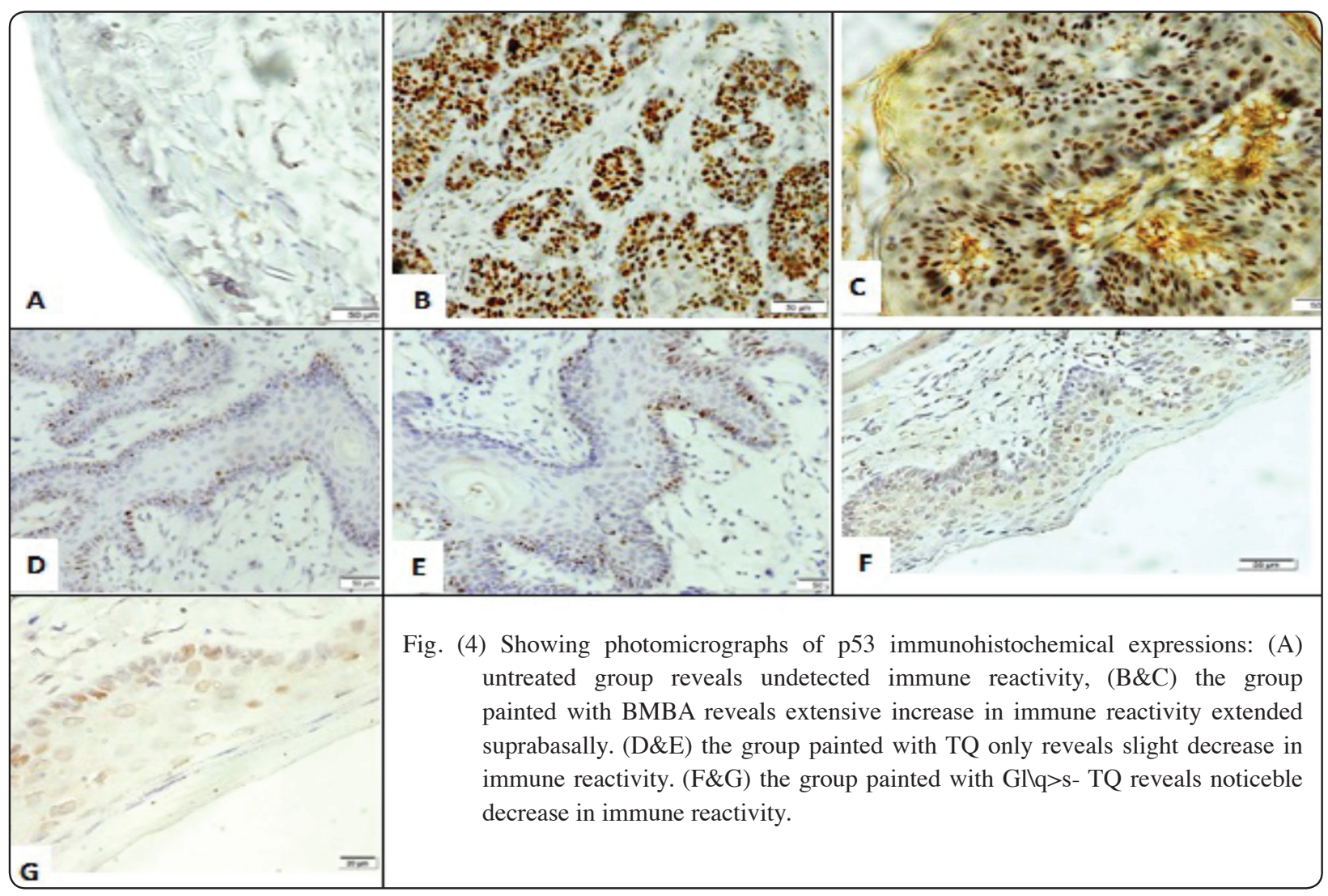


TABLE (1) Annova one way test

\begin{tabular}{|c|c|c|c|c|}
\hline & $\mathrm{N}$ & Mean & Std. Deviation & P value \\
\hline Negative group & 10 & 1.80 & .40 & \\
\cline { 1 - 4 } Positive group & 10 & 47.01 & 6.79 & \multirow{2}{*}{$<0.001$} \\
\cline { 1 - 4 } TQ & 10 & 25.48 & 3.84 & \\
\cline { 1 - 3 } GNPs-TQ & 10 & 15.82 & 1.65 & \\
\hline
\end{tabular}

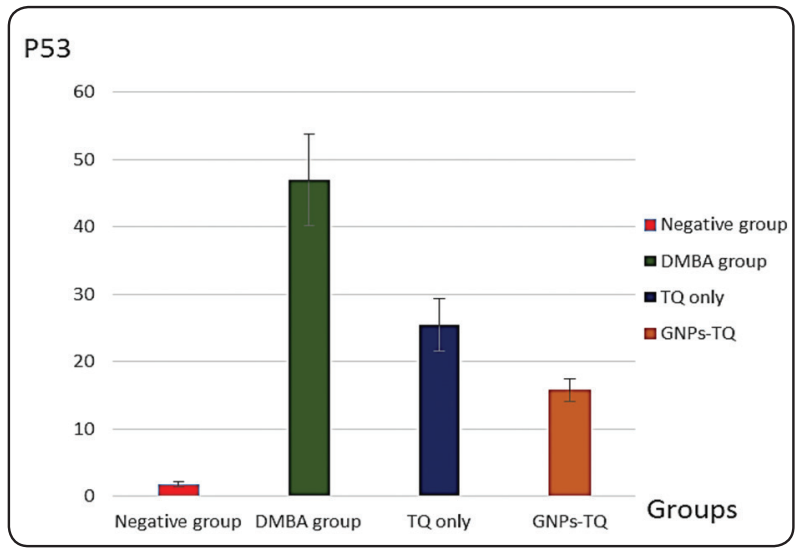

Fig. 5: representing as mean \pm standard deviations of $\mathrm{p} 53$ expression between negative group (red bar), DMBA group (green bar), TQ only (blue bar), and GNPsTQ(orange bar)

\section{DISCUSSION}

This study aimed to compare the topical chemopreventive effect of TQ only versus GNPsTQ through immunohistochemical detection of p53 in DMBA-induced oral carcinogenesis. In this work, the prepared GNPs were spherical, well dispersed, its particle size ranged between $25-30 \mathrm{~nm}$. Chithrani et $a l^{19}$ concluded that the cellular uptake of spherical GNPs is higher than rod-shaped counterparts. Several studies confirmed that GNPs cytotoxicity depends on their sizes. Particles larger than $15 \mathrm{~nm}$ were nontoxic. ${ }^{20,21}$ Other studies documented the biosafety of GNPs in experimental models after intraperitoneal injection through liver histology and blood markers analysis. ${ }^{22,23}$ Ultraviolet-Visible spectra for the prepared gold nanoparticles gave a sharp peak at $526 \mathrm{~nm}$ which confirmed gold nanoparticles formation. This result was in line with several studies reported the maximum peak at $529 \mathrm{~nm}$ and $522 \mathrm{~nm}$ respectively. ${ }^{24,25}$ Sharp peaks shifting to longer wavelength were noted with GNPs-TQ which indicated proper loading of TQ on GNPs. On line with the present result Daduang et $a l^{26}$ reported comparable deviation in the maximum peak after loading of gallic acid on GNPs from $525 \mathrm{~nm}$ to $560 \mathrm{~nm}$.

Topical application of GNPs-TQ $0.01 \mathrm{mg} /$ $\mathrm{kg}$ gave promising results in this study. This concentration was 10 -folds lower than a comparable study used TQ $0.1 \mathrm{mg} / \mathrm{kg}$ by intra-peritoneal route. ${ }^{17}$ A comparable dose reduction was observed in case of polylactic acid-polyethylene-glycol (PLA-PEG) encapsulated epigallocatechin-3-gallate (EGCG) ${ }^{27}$ Another study documented the efficacy of GNPsTQ $0.01 \mathrm{mg} / \mathrm{kg}$ in regression of malignancy through inhibition of NF- $\mathrm{KB}$ expression during treatment of OSCC by intraperitoneal injection. It might be due to proper distribution of GNPs-TQ on the cell membrane due to use of little amount of TQ that led to improvement of the cellular uptake. ${ }^{28}$ Soni et $\mathrm{al}^{29}$ reported that the nano-particles release the drug within the cells, not outside to increase the drug intracellular concentration. Hence, lower concentration would result in higher efficacy.

To ensure the topical chemopreventive effect of the used drugs; evaluation of the clinical, histopathological, and p53 immunohistochemical expression was done.

Clinically, in this study gross remarks were detected in DMBA-painted pouches for $14 \mathrm{w}$, like hair loss, skin ulcers, large exophytic masses, and significant shortening in pouchs' length. These observations were on line with other researchers..$^{17,28,30}$ The buccal necrosis might be due to local toxic effect of DMBA or local infection that led to severe inflammation. ${ }^{31,32}$ The group painted with TQ only gave slight decrease in the size of the lesions due to use of low concentration of TQ 
$(0.01 \mathrm{mg} / \mathrm{kg})$. The animals painted with GNPs-TQ showed the smallest masses in comparison to other groups with significant improvement in general health. These findings indicated the beneficial effect of loading GNPs with TQ to achieve favorable results. Significant pouch elongation was noted in this group which confirmed the direct effect on muscle regeneration rather than fibrosis. ${ }^{33}$ Myofibers regeneration begins with activation of myogenic precursor cells which proliferate and differentiate into multinucleated myotubes and myofibres. ${ }^{34}$ Fibroblasts begin to produce extracellular matrix (ECM) to restore the framework of the connective tissue surrounding the muscle fibers. ${ }^{35}$ Resident or infiltrated macrophages play prominent role in muscle repair through pro-inflammatory cytokines as tumor necrosis factor- $\alpha$ (TNF- $\alpha)$, interleukins (ILs), and cyclo-oxygenase-2 (COX-2). ${ }^{36}$

The histopathological findings in the present work in DMBA-treated group for 14w showed well to moderately differentiated squamous cell carcinoma with invading malignant epithelial islands and keratin pearls. These findings were supported by several authors. ${ }^{17,37,38}$ Topical application of TQ only and GNPs-TQ resulted in delaying the malignancy. The best result was noted with GNPs-TQ. The chemopreventive effect of TQ was related to its anti-inflammatory ${ }^{39}$, anti-apoptotic $\&$ cell cycle arrest ${ }^{40}$, anti angiogenic ${ }^{41}$ properties in addition to prevention of invasion and metastasis. ${ }^{42}$ To enhance the effect of TQ due to its hydrophobic nature, attempts were carried out to encapsulate TQ in different nano-formulations for better targeting of the cancer hallmarks. ${ }^{43,44}$ Nanoparticles can passively target tumor cells by an accumulation and entrapment process through enhanced permeation and retention (EPR) effect. It can be imposed by angiogenic vessels through leaky blood vessel (gaps 600nm). ${ }^{45}$ This concept allows selective penetration of the nanoformulations at higher levels than to normal cells.
Immunohistochemical evaluation of p53 in the present study in normal tissues of negative control group revealed negative nuclear expression. Due to the short half life time of wild p53 protein it is hard to be detected by immunohistochemical evaluation. ${ }^{46}$ In the present work, significant increase in the nuclear expression of p53 in all layers in DMBA-painted group was detected. A close relation between development of OSCC and alterations in the expression of tumor suppressor genes and oncogene was reported. ${ }^{47}$ These results were on line with several studies. ${ }^{48,49}$ Mutant p53 was reported as the most frequent alterations in OSCCs resulted in stabilization of the protein within the nuclei of malignant cells. ${ }^{46}$ Several studies reported that there was a strong relationship between increasing the positivity of p53 expression and the degree of tumors differentiation..$^{50,51}$ Baweja et al detected that suprabasal nuclear expression of p53 is an early event in oral carcinogenesis. Stronger staining had greater risk of malignancy progression. Only benign hyperplastic lesions didn't reveal any immune reaction..$^{52}$ In the present study, there was marked decrease in the nuclear expression of $\mathrm{p} 53$ when the pouches were painted with TQ, which is explained by the chemoprevention effect of thymoquinone. Other researchers reported the effect of thymoquinone on a number of carcinogenic signaling pathways or signaling molecules ${ }^{42}$. The decrease in p53 expression was more significant in GNPs-TQ treated group. This finding could be explained by delivering more particles to the targeted cells and the longer exposure to the anticancer drug when dealing with nanosized preparations. ${ }^{53}$ In connection with the above findings, Montazeri et al reported that p53 plays an important role in mediating the survival by dendrosomal nanocurcumin through antiproliferative effects and induction of apoptosis. ${ }^{54}$ Sulfikkarali and his colleagues studied the chemopreventive efficacy of free naringenin (NAR) and naringenin-loaded nanoparticles (NARNPs) in DMBA hamster buccal pouch. There was marked decrease in the expression 
of PCNA and p53 after oral administration of NARNPs rather than free NAR. ${ }^{49}$ Mirunalini et al examined the effect of Ellagic acid-chitosan nanoparticle on DMBA-induced hamster buccal pouch tumorigenesis against free Ellagic acid which had superior therapeutic activity. ${ }^{55}$

\section{CONCLUSION}

TQ loaded on GNPs $(0.01 \mathrm{mg} / \mathrm{kg})$ gave promising results in delaying of carcinogenesis process and improving the general health of the animals through significant decrease of p53 nuclear expression in comparison with free TQ.

\section{REFERENCES}

1. Chi AC, Day TA, Neville BW. Oral cavity and oropharyngeal squamous cell carcinoma-an update. Cancer J Clinicians.2015;65 (5): 401-421.

2. El-Mofty S. Early detection of oral cancer. Egypt J Oral Maxillofac Surg. 2010;1: 25-31.

3. Sharma N, Hosmani JV, Tiwari V. Epithelial dysplasia: Different grading system and its applications. J Int Oral Health 2010;2:1-16.

4. Gomes CC, Drummond SN, Guimaraes AL, Andrade CI, Mesquita RA, Gomez RS. P21/WAF1 and cyclin D1 variants and oral squamous cell carcinoma. J Oral Pathol Med 2008;37:151-156.

5. Shimada T, Fujii-Kuriyama Y. Metabolic activation of polycyclic aromatic hydrocarbons to carcinogens by cytochromes P450 1A1 and 1B1.Cancer Sci. 2004; 95(1):1-6.

6. Bode AM, Dong Z. Cancer prevention research then and now. Nature Rev Cancer. 2009;9: 508-516.

7. Randhawa MA, Alghamdi MS. A review of the pharmacotherapeutic effects of Nigella sativa. Pakistan J Med Res. 2002;41(2): 77-83.

8. Banerjee S, Padhye S, Azmi A, Wang Z, Philip PA, Kucuk O, Sarkar FH, and Mohammad RM. Review on molecular and therapeutic potential of thymoquinone in cancer. Nutr. Cancer. 2010;62(7):938-946

9. Majdalawieh AF, Fayyad MW, Nasrallah GK. Anti-cancer properties and mechanisms of action of thymoquinone, the major active ingredient of Nigella sativa. Crit Rev Food Sci Nutr. 2017;57(18):3911-3928.

10. Elmowafy M, Samy A, Raslan MA, Salama A, Said RA, Abdelaziz AE, El-Eraky W, El Awdan S, Viitala T. Enhancement of bioavailability and pharmacodynamic effects of thymoquinone via Nanostructured Lipid Carrier (NLC) Formulation. AAPS Pharm Sci Tech. 2016; 17(3): 663-672.

11. Alexis F, Pridgen E, Molnar LK, Farokhzad OC. Factors affecting the clearance and biodistribution of polymeric nanoparticles. Mol Pharm. 2008; 5:505-515.

12. Patra CR, Bhattacharya R, Mukhopadhyay D, Mukherjee P. Fabrication of gold nano-particles for targeted therapy in pancreatic cancer. Adv Drug Deliv Rev. 2010;62(3):346-361.

13. Partridge M, Costea DE, Huang X. The changing face of p53 in head and neck cancer. Int J Oral Maxillofac Surg. 2007; 36: 1123-1138.

14. Muller PA, Vousden KH. Mutant p53 in cancer: new functions and therapeutic opportunities. Cancer Cell. 2014; 25: 304-317.

15. Amir T, Fatma A, and Hakan A. Gold Nanoparticle Synthesis and Characterisation, Hacettepe J Biol \& Chem. 2009; 37: 217-226.

16. Banoczy J, Csiba A.Occurrence of epithelial dysplasia in oral leukoplakia.Oral Surg Oral Med Oral Pathol. 1976; 42(6):766-774.

17. El-Dakhakhny M, Hassan MA, Abd El-Aziz G. Effect of thymoquinone and poly-thymoqunione on chemicallyinduced oral epithelial dysplasia (experimental study). Int Acad Res J. 2009; 1(2): 107-117.

18. Broders AC. Squamous cell epithelioma of the lip. A study of five hundred and thirty-seven cases. Amer Med Ass J. 1920; 74:656-664.

19. Chithrani BD, Ghazani AA, Chan WC. Determining the size and shape dependence of gold nanoparticles uptake into mammalian cells. Nano Lett. 2006; 6:662-668.

20. Pan Y, Neuss S, Leifert A, Fischler M, Wen F, Simon U, Schmid G, Brandau W, Jahnen-Dechent W. Size-dependent cytotoxicity of gold nanoparticles. Small. 2007; 3:1941-1949.

21. Rieznichenko LS, Dybkova SM, Gruzina TG, Ulberg ZR, Todor IN, Lukyanova NY, Shpyleva SI, Chekhun VF. Gold nanoparticles synthesis and biological activity estimation in vitro and in vivo. Exp Oncol. 2012; 34(1):25-28. 
22. Muller AP, Ferreira GK, da Silva S, Nesi RT, de Bem Silveira G, Mendes C, Pinho RA, da Silva Paula MM, Silveira PCL. Safety protocol for the gold nanoparticles administration in rats. Mater Sci Eng C Mater Biol Appl. 2017;77:1145-1150

23. El-Mansy MN, Hassan MM, Abou El-Nour KM, El-Hosary WH. Evaluation the safety of thymoquinone loaded on gold nanoparticles in the treatment of hamster buccal carcin-ogenesis. Suez Canal Univ Med J. 2017; 20 (1): 20-28.

24. Afifi MM, El-Sheikh SM, Abdelsalam MM, Ramadan H, Omar TA, El-Tantawi M, Abdel-Razek KM, Mohamed M. Therapeutic efficacy of plasmonic photothermal nanoparticles in hamster buccal pouch carcinoma. Oral Med. 2013; 115(6): 743-751.

25. Mahmoud RH, Bayoumi DAM. Use of colloidal gold nanoparticles on initiated oral dysplasia of Syrian golden hamsters' pouches. Egypt Dent J. 2015; 61: 3665-3675.

26. Daduang J, Palasap A, Daduang S, Boonsiri P, Suwannalert P, Limpaiboon T. Gallic acid enhancement of gold nanoparticle anticancer activity in cervical cancer cells. Asian Pac J Cancer Prev. 2015;16(1):169-174.

27. Siddiqui IA, Adhami VM, Bharali DJ, Hafeez BB, and Asim M. Introducing nanochemoprevention as a novel approach for cancer control: proof of principle with green tea polyphenol epigallocatechin-3-gallate. Cancer Res. 2009;69: 1712-1716.

28. El-Mansy MN, Hassan MM, Abou El-Nour KM, ElHosary WH. Treatment of oral squamous cell carcinoma using thymoquinone loaded on gold nanoparticles. Suez Canal Univ Med J. 2017; 20 (1): 11-19.

29. Soni P, Kaur J, Tikoo K. Dual drug-loaded paclitaxelthymoquinone nanoparticles for effective breast cancer therapy. Nanopart Res J. 2015; 18:17-29.

30. El-Mansy MN, Hassan MMA, Hanora AA, Abde-Latif GA. Expression of B-cell lymphoma-2 (BCL-2) at late stages of hamster pouch DMBA carcinogenesis model. Egypt Dent J. 2014; 60(2): 2317-2326.

31. AL-Jawfi KAM, Hassan MMA, El-Gohary AM. Effect of Nigella sativa oil on the hamster lymphocytes secondary to DMBA-induced carcinogenesis. Suez Canal Univ Med J. 2008; 11(1):75-80

32. Manoharan S, Sindhu G, Nirmal MR, Vetrichelvi V, Balakrishnan S. Protective effect of berberine on expression pattern of apoptotic, cell proliferative, inflammatory and angiogenic markers during 7,12-dimethylbenz(a) anthracene-induced hamster buccal pouch carcino-genesis . Pak J Biol Sci. 2011;14(20):918-932.

33. Huard J, Li Y, Fu FH. Muscle Injuries and Repair: Current Trends in Research. J Bone Joint Surg Am. 2002; 84 (5): $822-832$

34. Massimino M, Rapizzi E, Cantini M, Libera L, Mazzoeni F, Arsian P and Carraro U. ED2+ macrophages increase selectively myoblast proliferation in muscle cultures. Biochem Biophys Res Commun.1997; 235: 754-759.

35. Lehto M, Duance VJ, Restall D. Collagen and fibronectin in a healing skeletal muscle injury: an immunohistochemical study of the effects of physical activity on the repair of the injured gastrocnemius muscle in the rat. BRJ Bone Joint Surg. 1985;67: 820-828.

36. Wynn TA. Cellular and molecular mechanisms of fibrosis. J Pathol. 2008;214: 199-210.

37. Hassan MA, El-Dakhakhny M. Effect of some Nigella sativa constituents on chemical carcinogenesis in hamster cheek pouch. J Egypt Soc Pharmacol Exp Ther. 1992;11: 675-677.

38. Nagini S, Letchoumy PV, Thangavelu A, and Ramachandran Cr. Of humans and hamsters: a comparative evaluation of carcinogen activation, DNA damage, cell proliferation, apoptosis, invasion, and angiogenesis in oral cancer patients and hamster buccal pouch carcinomas. Oral Oncol. 2009;45(6): 31-37.

39. Firdaus F, Zafeer MF, Ahmad M, Afzal M. Anxiolytic and anti-inflammatory role of thymoquinone in arsenicinduced hippocampal toxicity in Wistar rats. Heliyon. 2018; 4(6): e00650

40. Gali-Muhtasib H, Diab-Assaf M, Boltze C, Al-Hmaira J, Hartig R, Roessner A. Thymoquinone extracted from black seed triggers apoptotic cell death in human colorectal cancer cells via a p53-dependent mechanism. Int J Oncol. 2004;25: 857-866

41. Yi T, Cho SG, Yi Z, Pang X, Rodriguez M, Wang Y. Thymoquinone inhibits tumor angiogenesis and tumor growth through suppressing AKT and extracellular signalregulated kinase signaling pathways. Molecul Cancer Ther. 2008;7: 1789-1796.

42. Asaduzzaman Khan M, Tania M,Fu S, Fu J. Thymoquinone, as an anticancer molecule: from basic research to clinical investigation. Oncotarget. 2017; 18;8(31):51907-51919. 
43. Ong YS, Yazan LS, Ng WK, Abdullah R, Mustapha NM, Sapuan S, Foo JB, Tor YS, How CW, Abd Rahman N, ZakarialAnsarFH. Thymoquinoneloaded in nanostructured lipid carrier showed enhanced anticancer activity in 4T1 tumor-bearing mice. Nanomed. 2018;13(13):1567-1582.

44. El-Far AH, Al Jaouni SK, Li W, Mousa SA. Protective Roles of Thymoquinone Nanoformulations: Potential Nanonutraceuticals in Human Diseases. Nutrients. 2018;10(10): pii: E1369.

45. Huang Y, Yu F, Park YS, Wang J, Shin MC, Chung HS, Victor C, and Yang VC. Co-administration of protein drugs with gold nanoparticles to enable percutaneous delivery. Biomaterials.2010, 31, 9086-9091.

46. Chang KW, Sarraj S, Lin SC, Tsai PI, Solt D. P53 expression, p53 and Ha-ras mutation and telomerase activation during nitrosaminemediated hamster pouch carcinogenesis. Carcinogenesis. 2000; 21:1441-1451

47. Balaram P, Sridhar H, Rajkumar T, Vaccarella S, Herrero R, Nandakumar A, Ravichandran K, Ramdas K, Sankaranarayanan R, Gajalakshmi V, Muñoz N, Franceschi S. Oral cancer in southern India: the influence of smoking, drinking, paan-chewing and oral hygiene. Int J Cancer. 2002; 98(3): 440-445.

48. Subapriya R, Kumaraguruparan R, Nagin S. Expression of PCNA, cytokeratin, Bcl-2 and p53 during chemoprevention of hamster buccal pouch carcinogenesis by ethanolic neem (Azadirachta indica) leaf extract. Clini biochem. 2006;39( 11): 1080-1087.

49. Sulfikkarali N, Krishnakumar N, Manoharan S, Nirmal RM. Chemopreventive efficacy of naringenin-loaded nanoparticles in 7,12-dimethylbenz(a)anthracene-induced experimental oral carcinogenesis. Pathol Oncol Res. 2013; 19:287-296

50. Kaur J, MannanR, Manjari M, Bhasin TS, Sharma S. P53 Expression in oral squamous cell carcinoma as a predictor of high grade malignancy and regional metastasis - an experience from a tertiary care hospital. India J Pathol \& Oncol. 2017;4(4):591-594.

51. Gatoo MA, Dar AM, Siddiqui M. Correlation of P53 expression with different histological grades in oral squamous cell carcinoma patients from Northern India. J Cancer Oncol. 2018; 2(3): e000125.

52. Baweja P, Monappa V, Krishnanand G. P53 Immunohistochemical Staining Patterns in Benign, Premalignant and Malignant Lesions of the Oral Cavity: A Study of 68 Cases. J Interdiscipl Histopathol. 2013; 1(3): 113-121.

53. Krishnakumar N, Sulfikkarali N, Rajendra Prasad N, Karthikeyan S. Enhanced anticancer activity of naringeninloaded nanoparticles in human cervical (HeLa) cancer cells. Biomed Prev Nutr. 2011;1:223-231

54. Montazeri M, Pilehvar-Soltanahmadi Y, Mohaghegh M, Panahi A, Khodi S, Zarghami N, Sadeghizadeh M. Antiproliferative and Apoptotic Effect of Dendrosomal Curcumin Nanoformulation in P53 Mutant and WideType Cancer Cell Lines. Anticancer Agents Med Chem. 2017;17(5):662-673.

55. Mirunalini S, Arulmozhi V, Isabella S. Chemotherapeutic effect of Ellagic acid encapsulated chitosan nanoparticles on DMBA induced hamster buccal pouch carcinogenesis. J Chem \& Pharmaceut Sci. 2017;10(2): 963-971. 